\title{
A cross fertilization como instrumento gerador de inovação
}

\section{Souza, Patrícia de Melloa \& Conti, Giovanni Maria ${ }^{b}$}

${ }^{a}$ Departamento de Design,Universidade Estadual de Londrina,Brasil; Bolsista Produtividade em Desenvolvimento Tecnológico Fundação Araucária; patriciademellosouza@gmail.com

bipartimento di Design, Politecnico di Milano, Italia; giovanni.conti@polimi.it

\begin{abstract}
Resumo
O artigo aborda o processo de desenvolvimento de produtos orientado pela dinâmica da cross fertilization, que remete ao contexto das relações de contiguidade entre diferentes áreas do conhecimento. O conceito foi introduzido pelo matemático James Clerk Maxwell, e consiste na possibilidade de adotar inovações já experimentadas em campos distintos dando lugar a uma transferência de conhecimento entre setores. A sua aplicação como instrumento condutor de projeto no campo do design, tem demonstrado que esta transferência pode se manifestar de modo implícito - no caso de sentido ou significado que se transporta de uma entidade para outra; e de modo explicito - quando se trata de transferência de tecnologia, de fabricação ou de processo industrial que caracteriza um setor ou parte dele. No contexto das intersecções, este estudo aborda relações entre o design, a moda e a arquitetura. O pensamento estrutural tem direcionado cada vez mais os designers, que se apropriam de principios arquitetônicos para manipular a estrutura e o volume das vestimentas. Por outro lado, percebem-se materiais têxteis sendo transformados em estruturas duradouras. Identificam-se princípios condutores comuns que direcionam o pensamento projetual, bem como elementos que agem como ativadores de transferências de conhecimento e facilitadores de processos de geração inovativos. Dialogar com outros campos como forma de apropriação de novos conceitos, linguagens ou técnicas contribui para que o desenvolvimento de produtos, quer sejam físicos ou intangiveis, digam respeito ao novo. As atividades inovativas dos indivíduos e das organizações estão vinculadas à capacidade do aprendizado adquirido, que habilita construir novas representações dos ambientes e derivar-lhes novos usos. O argumento abordado no decorrer deste estudo comprova, mediante a análise das relações que se estabelecem entre os distintos setores, que é dentro das zonas de fronteira-aquele campo de intersecção que pode ser gerado entre uma área disciplinar e outra, que de fato são ativadas as dinâmicas que facilitam o surgimento de processos de inovação significativos. Confirma-se, portanto, a eficácia da cross fertilization como instrumento aplicado no campo do design.
\end{abstract}

Palavras chave: design, arquitetura, desenvolvimento de produto, cross fertilization, inovação. 


\begin{abstract}
The article deals with the product development process guided by the dynamics of the cross-fertilization, which leads to the context of contiguity relations between different areas of knowledge. This concept, introduced by mathematician James Clerk Maxwell consists of the possibility of adopting innovations that were already experienced in different fields giving way to a knowledge transfer between sectors. Its application as project conductive instrument in the field of design has shown that this transfer can manifest in an implicit way - in the case of meaning or significance that is transported from one entity to another; and explicit way - when it comes to technology transfer, manufacturing or industrial process featuring a sector or a part of it. In the context of the intersections, the present study addresses the relationship between design, fashion and architecture. The structural thinking has increasingly focused designers, who appropriate architectural principles to manipulate the clothing structure and volume. On the other hand, we realize that textile materials are being processed in durable structures. Principles common conductors are identified to drive architectural design thinking as well as elements that act as enablers of knowledge transfer and facilitators of innovative generation processes. Dialogue with other fields as a form of new concepts ownership, languages or techniques contributes to the development of products, whether physical or intangible, relate to the new one. Innovative activities of individuals and organizations are linked to learning ability acquired that empowers to build new representations of environments and derive them new uses. The argument discussed in the course of this study proves, by analyzing the relationships established between the different sectors that is within the border areas - that intersection field that can be generated from a subject area to another, which in fact activates the dynamics that facilitate the emergence of significant innovation processes. It is confirmed, therefore, the efficiency of cross-fertilization as a tool applied to the design field.
\end{abstract}

Keywords: design, architecture, product development, cross-fertilization, innovation

\title{
1. A cross fertilization
}

Adota-se o termo cross fertilization para indicar um fenomeno de interdisciplinaridade ou relação de contiguidade entre as diferentes áreas do conhecimento humano; não diz respeito a uma determinada área específica mas sim à fronteira, a "zona de pesquisa" que é gerada entre um dominio e outro. Segundo Conti (2007), o conceito foi introduzido pelo matemático James Clerk Maxwell, em 1878, e consiste na possibilidade de adotar inovações já experimentadas em campos distintos dando lugar a transferência de conhecimento entre setores. No contexto do projeto, é possível afirmar que se trata de uma capacidade de "visão" acerca do que já existe para criar algo novo. Afinal, a essência de qualquer processo de inovação é a recombinação original de elementos provenientes de conhecimentos novos ou daqueles já existentes.

Os processos de tranferência entre setores mercadológicos diversos como os de vestuário, calçados, acessórios, 'têxteis para mobiliário, entre outros, representam dinâmicas já consolidadas em determinados sistemas, a exemplo do Sistema Moda italiano. A partir dos anos 50 a Moda italiana desenvolveu uma prática de atividade de pesquisa, de projetação, de gestão e controle de processos de produção e 
distribuição do tipo implícito - aquele que se refere ao sentido ou significado que se transporta de uma entidade para outra. É como se nunca antes tivesse codificado de maneira mais científica as etapas, ações e combinações de atividades, que ao contrário, alguns outros setores orientados ao design já tinham esquematizado e já praticavam.

$\mathrm{Na}$ medida em que se observa a trajetória histórica da moda e se aprofundam as investigações nesse campo, se evidencia também a existência de uma relação muito estreita com a arquitetura e com o próprio espaço urbano. O processo de organização da indústria da moda pode ser correlacionado com a evolução da arquitetura contribuindo para elucidar o debate do início do século XX sobre a padronização arquitetônica - adotada como solução para os problemas individuais de estilo - e a identificação de tipos ideais. Para Quinn (2003), a relação da moda com o ambiente construído extrapola o limite das estruturas físicas e estende-se a outros aspectos que estabelecem a compreensão do espaço urbano, cuja essência híbrida, fragmentada e transitória , contribue para que tais conexões se desenvolvam. "Habitar, aqui, refere-se à relação da ocupação espacial entre o sujeito e o contexto no qual está inserido, assim, pode-se dizer que, tridimensionalmente construída, a roupa é um espaço no qual o corpo habita" (COUTO, 2010, p.135). Inúmeras são as conexões que se estabelecem a partir de tal premissa.

$\mathrm{Na}$ contemporaneidade, portanto, considera-se que o projeto dedicado aos mais diversos segmentos e ao sistema que é gerado em seu entorno é pensado de forma transversal, inserido no contexto dos fenômenos culturais, produtivos, midiáticos e consumistas. Isto significa que não basta elaborar o que se pretende: antes, deve-se analisar os processos que geram a intenção desta criação. Seria redutivo limitar-se à dimensão industrial e considerar o produto acabado como o único resultado deste desenvolvimento.

A moda, o design e até mesmo a arquitetura pertencem à ampla Cultura do Projeto onde se desenvolvem cenários complexos que consideram os objetos, os sistemas e os sinais que regulam as relações entre os seres humanos e seus contextos. Assim, qualquer atividade projetual participante desta cultura opera para que a realização de produtos, sejam eles físicos ou intangíveis, contemplem a história, a evolução e as mudanças da sociedade para a obtenção de resultados inovadores. Certamente o diálogo entre os campos do conhecimento como forma de apropriação de novos conceitos, técnicas e aquisição de competências além daquelas pertinentes à própria área poderá contribuir para gerar inovação.

Neste contexto, o presente artigo discute os processos de desenvolvimento orientados pela dinâmica da cross fertilization. Inicialmente abordam-se as interações projetuais e os aspectos ou elementos que podem agir como ativadores das dinâmicas de transferência de conhecimentos entre as áreas; na sequência, identificam-se princípios condutores comuns que direcionam o pensamento para projetar a arquitetura, o design ou a moda; finalmente apresenta-se um caso prático de aplicação da cross fertilization no desenvolvimento de produtos, no qual se evidencia o seu potencial como gerador de inovação.

\section{As inter-relações projetuais}

No processo projetual, áreas diferentes percebem problemas e soluções de formas diferentes. Apesar de concordar que a formação de projetistas tem algumas características muito comuns, Lawson (2011) adverte que é preciso cautela ao pressupor que todos os campos da atividade de projetar dividem o mesmo terreno. Existem algumas diferenças, em especial no que se refere ao conhecimento tecnológico requerido para alcançar os objetivos previstos. Os projetistas não decidem apenas o efeito que querem obter, mas precisam saber como obtê-lo: o arquiteto deve, por exemplo, entender as propriedades estruturais do concreto e do aço, enquanto o designer de moda tem que ter competência para avaliar os vários tecidos. Nesse sentido, continua o autor, com as tecnologias cada vez mais especializadas que pressupõem 
conhecimentos específicos de cada área, é preocupante que cada um esteja condicionado pela sua formação e pela tecnologia de processo que conhece, porque tal condição pode restringir, ao invés de aprimorar o pensamento criativo, essencial à projetação.

Por outro lado, para os inúmeros projetistas que se interessam por outros campos, utilizar a tecnologia que domina ou o material que conhece, de modo não habitual, isto é, se apropriando de práticas advindas de outras áreas, que não a sua, pode render bons resultados.

Da mesma forma, projetar produtos de outro segmento, utilizando os conhecimentos inerentes à própria área pode gerar novas possibilidades. Lawson (2011) ilustra tal aspecto quando relata que os projetistas de móveis costumam afirmar que conhecem as cadeiras projetadas por arquitetos. "Isso porque a maioria dos arquitetos está acostumada a manejar a madeira numa escala e num contexto diferentes e, portanto, já desenvolveu uma 'linguagem da madeira' com um sotaque arquitetônico perceptível." (LAWSON, 2011, p.60). As solicitações para se resolverem os problemas arquitetônicos que envolvem a madeira não são as mesmas requeridas pelo projeto de móveis. Apesar de não ser comum ver cadeiras de tijolos e nem edificações de polipropileno, continua o autor, ambas são possíveis. Justamente nisto reside o diferencial propiciado pelas conexões estabelecidas entre os diversos campos.

Determinados elementos, ações ou posicionamentos podem funcionar como ativadores das dinâmicas de transferência de conhecimentos entre as áreas, para facilitar o surgimento de processos de inovação significativos. Neste sentido, recentes alianças da moda com a tecnologia e a segurança imbuem as roupas do contemporâneo com muitos dos sistemas característicos dos ambientes arquitetônicos. Projetadas para fornecer ao usuário um sentido de refúgio e um grau de proteção contra a violência urbana, conferem maior funcionalidade por meio dos materiais e dispositivos tecnológicos e ampliam a mobilidade do corpo na medida em que permitem a interação com seus sistemas (QUINN, 2009).

O outro fator que vem contribuindo para a aproximação das áreas é o avanço tecnológico, que possibilita o acesso de arquitetos a softwares de design cada vez mais sofisticados. Com eles é possível gerar formas mais complexas, muitas vezes referenciadas nos métodos de construção e manipulação de planos utilizados pela moda, que acumula uma longa história de lidar com a complexidade formal e construtiva. A transmutação de técnicas entre as áreas tem sido facilitada pelos avanços na tecnologia dos materiais e no incremento da tecnologia digital, além da globalização, que permite rápida disseminação de tudo que se desenvolve.

Para Dominoni e Tempesti (2012), explorar a realidade do design contemporâneo pelo ponto de vista das estruturas têxteis, permite evidenciar a importância do material como fator determinante de qualquer projeto. Lerma, Giorgi e Allione (2011), confirmam que a pesquisa de materiais está cada vez menos condicionada à tradicional segmentação por setores, e a investigação é conduzida no sentido de estudar e confrontar as inúmeras soluções possíveis, a fim de contemplar os conhecimentos dos diversos campos. A própria necessidade de projetar novos materiais e de unir tantas informações, constitui-se numa demanda dos distintos segmentos.

Em períodos anteriores, no entanto, já se evidenciava a crescente importância dos têxteis para arquitetos e designers de produtos. O interesse do designer catalão Martin Ruiz de Azúa por abrigos têxteis, por exemplo, resulta no projeto da Casa Básica, datado de 1999, que é uma casa que pode ser levada no bolso. Segundo Colchester (2009), ela transmite uma visão extrema do futuro, de edifícios que se materializam e se desmaterializam quando não são mais necessários; e de cidades onde as pessoas vivem como nômades em casas infláveis que se dobram e viajam com elas para onde quer que seja. Feita de poliéster dupla-face metalizado, permite o uso de um lado e do outro conforme a necessidade de proteção contra o calor ou o 
frio; pesa apenas 200 gramas e pode ser inflada pelo calor do sol, ou pelo calor do corpo do próprio usuário.

Esses espaços que se configuram como infláveis, que atualmente são utilizados também para exposições, podem ser montados e desmontados com grande rapidez, tendo suas dimensões consideravelmente reduzidas quando deflacionados. Tais estruturas itinerantes revelam o potencial da arquitetura para se tornar móvel e portátil, estabelecendo grande similaridade com produtos do vestuário.

Outros pontos congruentes que remetem à transferência de conhecimento são evidenciados por Geisel e Souza (2012), ao relacionarem a concepção do projeto do produto de moda com a concepção do projeto arquitetônico. Aspectos relevantes para o desenvolvimento de edificações, tais como: as necessidades dos habitantes com relação à construção, as condições do terreno e o entorno, podem ser - na moda, comparados à importância de conhecer o corpo do usuário, suas demandas e o meio no qual se insere.

O conforto é uma rede de inter-relacionamento que se conecta com as características do sujeito, do objeto e do ambiente, em determinado contexto (SILVA, 2010). Para desenvolver um projeto arquitetônico que atente para o conforto térmico do usuário, alguns aspectos devem ser observados, como a orientação quanto à insolação, o aproveitamento da ventilação natural e o sombreamento da fachada, entre outros.

Torna-se possível importar o conceito de conforto térmico da arquitetura para o campo da moda, estabelecendo um diálogo entre os dois campos do saber. A arquitetura é responsável pela criação de espaços confortáveis, assim como a moda é responsável pelo conforto do usuário na sua relação com o traje. Neste sentido, justifica-se o paralelo estabelecido entre as estruturas arquitetônicas que garantem o conforto térmico nas edificações e os recursos empregados na construção do produto do vestuário de moda que interferem diretamente no conforto térmico do usuário. O conforto trata da comodidade e do bem-estar e afeta diretamente a qualidade e o modo de vida do usuário, interferindo nas suas sensações e percepções (SOUZA, 2006). A arquitetura busca a harmonização das construções ao clima e às características locais, transformando os espaços construídos em espaços confortáveis, utilizando-se de recursos que favoreçam a iluminação e ventilação naturais.

\section{Os princípios condutores}

Ao longo da trajetória projetual, distintos graus de importância são conferidos aos vários aspectos do problema que são abordados levando em consideração as motivações, as crenças e os valores, que juntos, compõem a bagagem intelectual e cultural de cada um e definem maneiras peculiares de projetar. Esse conjunto, seja ele traduzido por uma série de ideias desarticuladas ou por um coerente método de projeto, é denominado por Lawson (2011) de princípios condutores - aqueles que direcionam e conduzem os processos projetuais individuais.

Em determinados contextos, constituem-se verdadeiras estratégias construtivas, em outros, podem surgir como resposta a uma necessidade gerada por uma restrição de projeto. De um lado, os princípios condutores influenciam e determinam a trajetória de cada processo. Do outro, como o aprendizado do projeto está na experimentação do seu fazer, cada problema solucionado permite ao projetista lidar com as diversas naturezas das restrições, e aprender mais sobre elas, de modo a materializar as suas ideias com clareza cada vez maior.

Estudos de registros de processos de projeto comprovam que não existe uma rota única para transitar entre a definição inicial do problema que desencadeia tal processo, e a solução final encontrada. No entanto, identificam-se alguns princípios condutores comuns, que direcionam o pensamento ao projetar. 
No contexto da presente pesquisa, eles se revestem de um caráter especial porque são flagrados na condução de projetos absolutamente distintos que permeiam áreas do conhecimento, as mais diversas.

Em 1898, afirma Quinn (2003), ao identificar na vestimenta uma forma de abrigo para o corpo, o arquiteto Adolph Loos, autor da obra The Principle of Dressing, sugere que o conhecimento próprio da engenharia têxtil, bem como suas técnicas, sejam empregados como princípios construtivos das edificações. Ao serem aplicados em materiais mais rígidos que os têxteis poderiam estruturar espaços mais amplos. Ao traçar tal paralelo, possivelmente Loos tenha sido um dos primeiros a estabelecer conexões entre moda e arquitetura a partir de um pensamento direcionado por aspectos de estrutura.

A ideia de honestidade estrutural, tão difundida no período do Modernismo, mostra como os elementos estruturais podem ser parte essencial dos princípios condutores. Insere-se neste caso o projeto de Bill Howell para o University Centre, em Cambridge, que se enquadra na filosofia de edificação chamada de arquitetura vertebrada na qual a forma final é gerada a partir da estrutura, tendo seu volume interior definido e articulado por ela. Trata-se de um processo guiado por um conjunto de princípios a respeito do papel da estrutura para desenvolver a anatomia de cada edificação.

Outro projetista que se enquadra neste contexto é o espanhol Santiago Calatrava, que apesar da dupla formação em arquitetura e engenharia, é um estudioso do corpo humano - como os designers de moda além de fascinado pela sua capacidade de se mover e assumir uma série de configurações completamente estáveis e resistentes. Demonstra grande interesse por estruturas móveis e dobráveis e seus projetos refletem a ideia de equilíbrio dinâmico. Justifica-se, assim, a afirmação de que seu processo projetual é, em grande parte, conduzido por princípios estruturais e que se apropria de conhecimentos advindos de outras áreas para projetar a sua. Em geral estas estruturas transformam-se em elementos esculturais de grande apelo estético, como comprovam duas de suas recentes obras, inauguradas em dezembro de 2015 e março de 2016, respectivamente: o Museu do Amanhã no Rio de Janeiro e a estação de trens do World Trade Center em Nova York.

Conduzidos pelo mesmo pensamento estrutural, profissionais da moda utilizam princípios arquitetônicos para manipular a estrutura e o volume das vestimentas: Ralph Rucci, Junya Watanabe, Teng e Isabel Toledo, cada um a seu modo, aplicam princípios de suspensão para estruturar seus produtos. Em uma das coleções, Watanabe mostra produtos em nylon com mecanismos e estruturas semelhantes ao modo como um paraquedas aberto pode ser manipulado por suas alças - apesar do emprego de um material rígido como o nylon é relevante a delicadeza transmitida pelas peças; Teng apresenta vestidos com cabos que içam o tecido de uma maneira similar às estruturas das pontes suspensas (HODGE, 2007).

$\mathrm{Na}$ medida em que, arquitetos e designers, interpretam estratégias de trabalho uns dos outros, forjam novas conexões. Segundo Quinn (2009), novos paradigmas da arquitetura estão a transformar as técnicas de alfaiataria e os materiais têxteis em estruturas duradouras, aproximando edifícios de produtos do vestuário para que possam ser igualmente concebidos como uma série de estruturas permanentes $\mathrm{e}$ habitações portáteis. Assim como os designers utilizam materiais macios e métodos de costura para projetar abrigos portáteis, arquitetos implantam técnicas semelhantes para promover novas redes estruturais, e edifícios móveis.

As novas tecnologias têxteis vêm, gradualmente, modificando o caráter e a forma de edifícios permitindo aos arquitetos explorar a geometria orgânica. A pesquisa acerca de formas naturais como as das teias de aranhas ou das bolhas de sabão que vinham sendo estudadas, é ampliada pelo uso do design e da manufatura auxiliados por computador. Formas como estas foram elaboradas por arquitetos australianos para o projeto do National Swimming Centre, construído para as Olimpíadas de Pequim, em 2008, mais conhecido como Water Cube. Segundo Colchester (2009), centenas de formas diferentes de almofadas 
criam uma estrutura não linear, aparentemente casual, mas de grande complexidade, que não teria sido possível construir três anos antes. As almofadas são arranjadas de tal modo que conferem ao edifício uma aparência acolchoada que lembra a superfície dos tecidos em matelassê, muito empregada no vestuário de moda.

Flexibiliza-se, portanto, o conceito de construção e abordam-se diferentes formas de construir, identificando princípios similares que estruturam tanto o produto de moda quanto a edificação, evidenciando um pensamento construtivo análogo entre as áreas.

\section{Piquadro: um estudo de caso $^{44}$}

Para melhor ilustrar os processos relacionados à cross fertilization bem como evidenciar a aplicabilidade deste instrumento como gerador de inovação, optou-se por abordar o estudo de caso realizado por Giovanni Maria Conti, na Piquadro, o que possibilitou seu confronto direto com a realidade da empresa e com o seu fundador, Marco Palmieri, cuja entrevista concedida fundamenta este texto.

Piquadro é uma empresa italiana fundada em 1987, que trabalha o couro com maestria artesanal e tecnologia de ponta. Oferece uma ampla gama de produtos e acessórios de alta qualidade no que diz respeito aos materiais e ao design. A filosofía se traduz em uma série de objetos que vão desde agendas, pastas porta-documentos e carteiras, aos bolsões de viagem, entre outros, desenvolvidos para responder as exigências de praticidade cotidiana e ao gosto estético, onde o acabamento feito à mão personaliza um estilo inconfundível. A empresa começou como fabricante de outras marcas de luxo italianas e, a partir de1998, iniciou a produção de artigos de couro da própria marca.

O estudo abordou os seguintes aspectos: o diálogo entre a moda e o design percebido na empresa e o início desta hibridação; o processo produtivo; a comunicação;a visibilidade externa; a lógica estabelecida entre local e global.

Em determinado momento percebeu-se a necessidade de mudar o foco da empresa para transformá-la em "marca" e foi preciso alterar aspectos empresariais para contemplar tal decisão. Resolveu-se dar um direcionamento centrado no valor cultural e aspiracional do design, que é diferente da abordagem da moda para inúmeros fatores. A moda é mais propensa ao impulso e em alguns aspectos vinculada a um consumidor mais superficial do que o consumidor do design que talvez seja mais atento e pese mais a relação com o dinheiro, com o produto, com a funcionalidade e a utilidade. Neste caso, o valor dado ao produto é outro e isto determina grande diferença na motivação para a tomada de decisão de compra.

Definiu-se por este posicionamento de marca porque no mercado não havia ninguém que produzisse artigos de couro voltados para o design e para a funcionalidade do produto. A empresa soube comunicar de modo claro e coerente quem queria como cliente e a quem aspirava com a sua imagem técnica, de design, de função, de conforto e uso, em comparação com a linguagem mais lúdica, em alguns aspectos, da moda.

Este novo modo de pensar deveria, então, ser comunicado e traduzido em produto. Embora se tratassem de produtos clássicos que não demandavam nenhum tipo de tecnología específica, uma série de funcionalidades foram acrescentadas.

\footnotetext{
${ }^{44}$ A íntegra do estudo de caso "Piquadro: la pelletteria tech-inside" abordado neste artigo de modo sintético, encontra-se publicada na Magazine della Ricerca SDI. Design ReView n 4: "Moda e Design. Cross Fertilization per l'Innovazione". Edzioni Poli.design, 2006.
} 
O primeiro aspecto estudado foi a "pega" que deveria ser ideal e possibilitar uma sensação tátil de prazer. Para tanto, foram acolchoadas e preenchidas internamente, de modo que cada vez que era tocada dava a sensação de se ter na mão algo extremamente agradável, assim como uma espuma. Em seguida, vieram as bolsas masculinas com porta guarda-chuva: o compartimento posicionado do lado de fora, não só recobria o guarda-chuva depois do uso como também evitava que o conteúdo interno se molhasse. Além disso, as bolsas mais tradicionais foram estudadas a partir de outro ponto de vista: se girar, de um certo modo, tornam-se mochilas, portanto, se o usuário se locomovesse em uma scooter, poderia mantê-la em seus ombros e não a tiracolo. Outras bolsas foram pensadas para acomodar o capacete ao invés dele ficar sobre o assento da moto quando retirado: nelas há um ziper que se abre e dali pode ser retirado um compartimento confeccionado em material elástico no qual se guarda o capacete. Estes pequenos detalhes fizeram diferença e foram percebidos por aquele comprador um pouco mais racional.

É na Cultura do Projeto Industrial, portanto, e nas suas habilidades projetuais desenvolvidas na tradição do "saber fazer" italiano que a empresa se referencia para projetar os acessórios de viagem, que partem do compromisso de querer satisfazer as necessidades e as exigências demandadas pela sociedade. Trata-se de uma contínua pesquisa de estímulos e sensações que através dos objetos Piquadro vão sendo transmitidas aos consumidores.

No estudo de caso fica evidenciado como o objeto da pesquisa ativada pela Piquadro pode conduzir a empresa para identificar as metodologias de projeto e de gestão de recursos criativos para apoiar os processos de inovação, do tipo transversal, entre moda e design. É a Cultura do Projeto industrial o fator determinante que entra na atividade projetual da empresa e que influencia significativamente os processos, a organização e a estruturação produtiva. A necessidade de hibridação de competências entre as diferentes áreas do projeto acaba por ser a única chave de leitura para compreender o produto Piquadro.

Muitas empresas do setor da moda ainda tem operado de modo isolado, não explorando o potencial de colaboração com outros setores mercadológicos. Na Piquadro, a consciência de implementar dinâmicas de inovação relacionadas com os processos de transferência de conhecimento - cross fertilization - que podem levar à identificação e à experimentação de competências, processos projetuais e modelos organizacionais com capacidade de operar dentro do todo do sistema projetual, parece ter se tornado uma prática metodológica de trabalho.

Outro aspecto relevante é o fato do interesse de Marco Palmieri, pela eletrônica e pela tecnologia da informação, ter sido transferido para os processos industriais utilizados para a produção de seu produto. Considerando a importância do couro na economia do processo de produção do produto buscou-se otimizar a fase de processamento inventando um sistema de corte diferenciado que corta o couro por meio de jato de água. Até então os sistemas automatizados só eram utilizados para o corte de tecidos e não para o couro, devido à sua irregularidade e às especificidades do material. Desenvolvido internamente pela Piquadro foi posteriormente vendido a empresa francesa Lectra, líder mundial nos sistemas automatizados para tecidos, que assumiu a tecnologia e se tornou parceira.

Da mesma forma aplicou-se os conhecimentos advindos da tecnología da informação para descobrir como sistematizar o estoque e torná-lo flexível para as vendas on-line e para o abastecimento das lojas. Criou-se um sistema eficaz totalmente automatizado, sem a necessidade de operador. A empresa acredita que o fator estratégico para o êxito é ser inovadora, tanto na abordagem quanto no posicionamento, seja nas questões de mercado, marca ou produto. $\mathrm{O}$ fato de Marco Palmieri afirmar que não encontrou ninguém capaz de combinar o conhecimento do setor de couro com os processos de TI, e então ele mesmo com seus conhecimentos de informática trabalhou pessoalmente para o desenvolvimento de um sistema de controle de toda a cadeia, admite a necessidade da transferência de conhecimentos dos 
diferentes âmbitos disciplinares para a construção de um projeto global, que tem a inovação como valor agregado e elemento distintivo.

Assim, no contexto das reflexões sobre dinâmicas de inovação relacionadas com os processos de cross fertilization, Piquadro classifica-se como um modelo de sucesso.

Detecta-se que a necessidade de inovação, mesmo em setores maduros do mercado, ainda é um grande desafio e evidencia-se a complexidade projetual do objeto fashion design oriented, no qual o valor agregado não é simplesmente uma bela forma ou uma bela cor mas a história - vinculada ao produto que a empresa é capaz de construir e transmitir para o consumidor.

\section{Considerações finais}

$\mathrm{O}$ argumento abordado no decorrer da pesquisa - em especial, no caso Piquadro - permite definir a inovação como um processo de mudança evolutiva que possibilita às organizações desenvolver-se. No âmbito da empresa investigada, a cross fertilization atuou como: ferramenta estratégica para a inovação de produtos e processos; prática metodológica para a busca do novo; fonte de conhecimento continuamente alimentada pela curiosidade da pesquisa.

A análise das intersecções que se estabelecem entre os distintos campos comprova que é dentro destas áreas de fronteira que são ativadas de fato as dinâmicas que facilitam os processos de inovação significativos. O pensamento projetual denota uma troca contínua e um diálogo constante entre conhecimentos diversos e diferentes métodos de abordagem à projetação.

A inovação é para o design e para a arquitetura fonte de constante mudança e lugar para a experimentação ; em um contexto mais amplo de sistema-produto, onde a moda é um dos muitos fenômenos produtivos de diversas categorias mercadológicas, hoje é necessário assumir uma visão sistêmica do próprio processo de inovação. É cada vez mais evidente que se esteja passando da projetação de um produto à projetação de um processo que, em seguida, trará possíveis repercussões para o sistema de produtos, sejam eles físicos ou intangíveis. A palavra sistema refere-se as atividades típicas dos setores, que passam a se integrar e a configurar cenários, isto é, aqueles lugares nos quais se realiza o cruzamento de experiências e se efetiva, de fato, a cross fertilization.

Dentro deste contexto que define a contemporaneidade - um cenário dinâmico, fluido, complexo, mutante e imprevísível onde várias realidades convivem de forma simultânea - é possível vilumbrar as contribuições do presente estudo para outros campos. Este panorama impõe contínuas adaptações e a reorganização dos sistemas nos diversos níveis, favorecendo a interação de forma transversal entre os setores.

Acredita-se, portanto, que a cross fertilization possa ser aplicada a outros campos, bem como dar origem a processos a partir do contato com outros conhecimentos codificados, sejam eles, projetuais, técnicos, profissionais, culturais ou outros ampliando-se, assim, a abrangência da inovação - prerrogativa do design, da arquitetura e da moda. 


\section{Referências}

BERTOLA P. y MANZINI E. (2004). Design multiverso. Milano: POLI.design publications.

COLCHESTER, Choloë. (2009). Textiles today: a global survey of trends and traditions. London: Thames \& Hudson.

CONTI, G. M.(2007). Moda e cultura del progetto industriale: cross fertilization per i'nnovazione. Tesi (Dottorato in Disegno Industriale e Comunicazione Multimediale, XIX ciclo) - Scuola di Dottorato. Milano: Politecnico di Milano.

CONTI, G.M. (2012). Cross Fertilization: un approccio al progetto per la moda. Milano : Mondadori Università, ebook.

CONTI, G.M. (2012). "Moda e Design. Cross Fertilization per l'Innovazione" en Magazine della Ricerca SDI (2006). Design ReView n 4: Edzioni Poli.design.

COUTO MELLO, M. M. (2010). Modas, arquiteturas e cidades: interfaces, conexões e interferências. Tese (Doutorado em Arquitetura), Salvador: Universidade Federal da Bahia,

DOMINONI, A. y TEMPESTI, A. (2012). Forma e materia: design e innovazione per il tessile italiano. Milano: Maggioli.

FIORANI E. (2004). Abitare il corpo: la Moda. Milano : Lupetti.

FIORANI, E. (2006). Moda, corpo, immaginario. Milano : Edizioni POLI.Design.

FLUSSER, V. (2003). Filosofia del Design. Milano : Bruno Mondatori.

GIESEL, A. y SOUZA, P.M. "The correlation between thermal comfort in buildings and fashion products" en World Congress on Ergonomics (18, 2012). Recife: IOS Press, p. 5561-5563.

HODGE, B. (Org.).(2007). Skin + bones: parallel practices in fashion and architecture. London: Thames \& Hudson.

LAWSON, B. (2011). Como arquitetos e designers pensam. São Paulo: Oficina de Textos.

LERMA, B., DE GIORGI, C. y ALLIONE, C. (2011). Design e material: sensorialità, sostenibilità, progetto. Milano: Francoangeli.

PUGLISI G. (2001). I modi della moda. Palermo : Sellerio Editore.

QUINN, B.(2009). "The fashion of architecture" en Brand, Jan; Teunissen, J. Fashion and imagination about clothes and art. pp.260-275. Arnhem: ArtEZ.

QUINN, B. (2003). The fashion of architecture. New York : Berg Oxford.

RULLANI, E. (2000). "Crescita e innovazione nel Made in Italy” en Quadro Curzio, A. y Fortis, M. Il made in Italy oltre il 2000. Innovazione e comunità locali. Bologna : Il Mulino.

SILVA, L. "Aspectos teóricos do conforto sob o ponto de vista da ergonomia" en Congresso Brasileiro de Ergonomia (16, 2010). Rio de Janeiro: ABERGO.

SOUZA, P.M. y CONTI, G.M. (2015) . "Projetando para a inovação: a Cross Fertilization como método" en CUICIID 2015 Congreso universitario internacional sobre la comunicación en la profesión y en la universidad de hoy: contenidos, investigación, innovación y docencia. Madrid : Universidad Complutense.

SOUZA, P.M. (2013). Estratégias de construção para estruturas têxteis vestiveis. Tese (Doutorado em Design) Faculdade de Arquitetura, Artes e Comunicação. Bauru: Universidade Estadual Paulista

SOUZA, P.M. (2006). A modelagem tridimensional como implemento do processo de desenvolvimento do produto de moda. Dissertação (Mestrado em Design) - Faculdade de Arquitetura, Artes e Comunicação. Bauru: Universidade Estadual Paulista . 